\section{ENGEVISTA}

Página da revista: http://www.uff.br/engevista/seer/

\title{
Experimental analysis of heat-pump integrated with solar energy
}

\author{
André Ricardo Quinteros Panesi ${ }^{1}$
}

\begin{abstract}
The objective of the present work is to analyze the performance of an equipment used in water heating for domestic and commercial use. The hot water is obtained by conventional vapor compression heat pump machine, using the R-134a as primary fluid refrigerant. This way, the plate evaporator is in contact with the hot source originated from incandescent lamp, simulating the solar energy and the condenser is in contact with the cold source represented by the water storage. A radiator is used to collect the hot water that comes from the hot water storage. The parameters analysed in the research are the energy dissipated by the radiator, the $\mathrm{COP}$ of systems and the variation of the water flow rate.
\end{abstract}

Keywords: Heat-pump, thermal energy storage, solar energy. 


\section{Introduction}

Heat pumps can use many sources to provide energy to heat the working fluid, generally using electricity or gas. The solar energy also represents an interesting source, after all is a free energy. Heat pump water heaters utilizing solar energy have received a higher degree of attention in the literature and hence shall be discussed here. According to Hepbasli et al. (2009), with water heating being the second largest use of home energy in most locations, there has been renewed interest in the development and use of energy-conserving domestic water heater since the 1973 oil embargo. Also was made several information about heat pump water heater (HPWH) operated on an electrically driven vapor-compression cycle and pumps the energy from the air in its surroundings to water in a storage tank. In accordance with Wang, et al. (2007) was made one experimental research under typical spring climate in Shanghai with direct expansion solar- assisted heat pump to water heater. The authors analyzed the performance with results of exergy analysis, been able to calculate that the highest exergy loss occurs in the compressor, followed by collector evaporator, condenser and expansion valve, respectively. Solar two-stage direct expansion assisted by heat pump for high temperature applications were analyzed. Comparisons between the solar two-stage and the single-stage direct expansion, assisted by heat pump systems were performed and presented, see Chaturvedi et al. (2009) for more details.

According to Bakirci et al. (2011), a solar source heat pump system was experimentally investigated. The authors investigated the COP of the whole system and the heat pump systems. Besides, they also highlighted the solar source heat pump systems as presenting tremendous environmental benefits when compared to the conventional systems. Moreno et al. (2012), proposed the development of a theoretical model to determine the operating parameters and consumption of a domestic hot water installation, which uses a direct expansion solar-assisted heat pump. The model's results have been compared and validated the experimental results obtained with the equipment installed at the Charles III University of Madrid. In accordance with Banister et. al. (2014) a computer's model was validated for an experimental test apparatus and a method were presented for testing multiple configurations of solar-assisted heat pump systems. The performance of many system components is dependent on the fluid temperature(s) at the inlet and the experiments conducted indicated that thermal storage tank models are a key factor determining the accuracy of overall results. By means of Wagar et. al. (2014) the work explores the operation and performance of a solar-assisted heat pump system which employs a single domestic hot water (DHW) tank. The simulations tool is validated using a purpose-built experimental test apparatus and it was noted that the biggest discrepancies between model and experimental test is the response rate of temperature changes. 


\section{Experimental setup}

Fig.1 shows a schematic diagram of the experimental setup. The thermal storage tank is made of steel with $350 \mathrm{~mm}$ internal diameter, $1500 \mathrm{~mm}$ in length, and $10 \mathrm{~mm}$ thickness, insulated by a $50 \mathrm{~mm}$ layer expanded polyurethane. The refrigeration unit is a simple vaporcompression cycle, operated with R-134a. It includes a hermetic compressor (1/4hp), condenser (natural type), filter drier, thermostatic expansion valve, a plate evaporator with $1.6 \mathrm{~m}^{2}$ area and radiator with total area of $0.63 \mathrm{~m}^{2}$.

The measuring unit consists of 11 platinum resistance temperature sensors (Pt100) and a flow meters to measure the volumetric water flow rate. Also is used the data acquisition unit and a personal computer for data recording and analysis. Temperature and flow rate measure points were arranged accordingly in the system, and the measuring range and the accuracy of measurement devices are listed in Table 1.

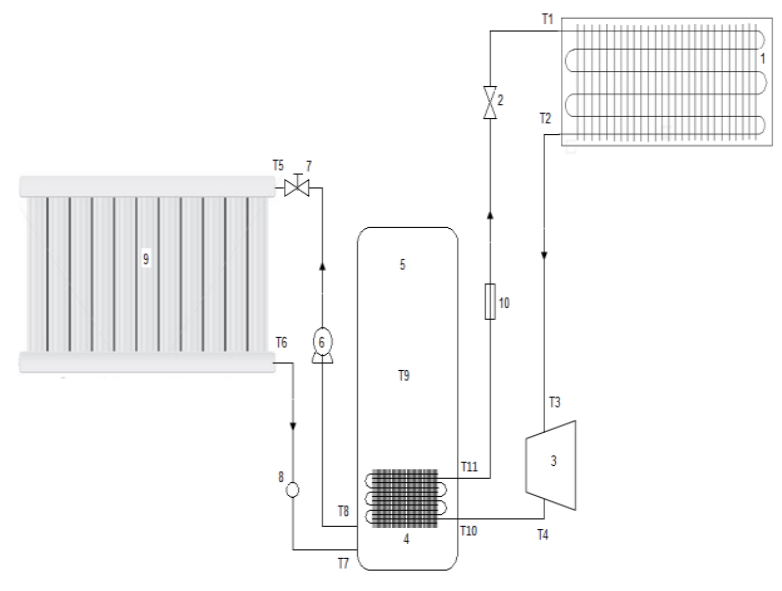

Figure 1: Schematic diagram of experimental setup. (1) plate evaporator, (2) expansion valve, (3) hermetic compressor, (4) condenser, (5) thermal storage tank, (6) circulating pump, (7) flow control valve, (8) Digital flow meter, (9) radiator, (10) filter drier.

Table 1:Range and accuracy of measurement devices

\begin{tabular}{ccc}
\hline $\mathrm{N}^{\circ}$ & Measuring point name & Device accuracy \\
\hline $\mathrm{T} 1$ & Inlet coolant temperature in the plate evaporator & $\pm 0.3^{\circ} \mathrm{C}$ \\
$\mathrm{T} 2$ & Outlet coolant temperature in the plate evaporator & $\pm 0.3^{\circ} \mathrm{C}$ \\
$\mathrm{T} 3$ & Suction temperature of the compressor & $\pm 0.3^{\circ} \mathrm{C}$ \\
$\mathrm{T} 4$ & Discharge temperature of the compressor & $\pm 0.3^{\circ} \mathrm{C}$ \\
$\mathrm{T} 5$ & Inlet water temperature in the radiator & $\pm 0.3^{\circ} \mathrm{C}$ \\
$\mathrm{T} 6$ & Outlet water temperature in the radiator & $\pm 0.3^{\circ} \mathrm{C}$ \\
$\mathrm{T} 7$ & Inlet water temperature in the thermal storage tank & $\pm 0.3^{\circ} \mathrm{C}$ \\
$\mathrm{T} 8$ & Outlet water temperature in the thermal storage tank & $\pm 0.3^{\circ} \mathrm{C}$ \\
$\mathrm{T} 9$ & Temperature in the termal storage tank & $\pm 0.3^{\circ} \mathrm{C}$ \\
$\mathrm{T} 10$ & Inlet coolant temperature in the condenser & $\pm 0.3^{\circ} \mathrm{C}$ \\
$\mathrm{T} 11$ & Outlet coolant temperature in the condenser & $\pm 0.3^{\circ} \mathrm{C}$ \\
$\mathrm{F} 1$ & Volumetric flow rate of the water & $0.5 \%$ \\
\hline
\end{tabular}


ISSN: $1415-7314$

ISSN online: $2317-6717$

Figure 2 through 5 shows the photographs of the experimental setup and PC data acquisition system.

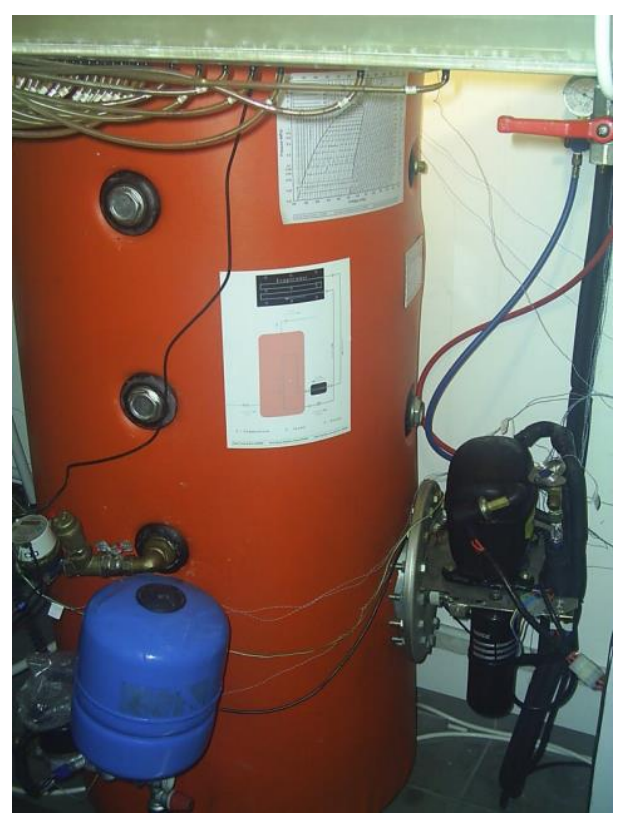

Figure 2: Thermal storage tank and compressor

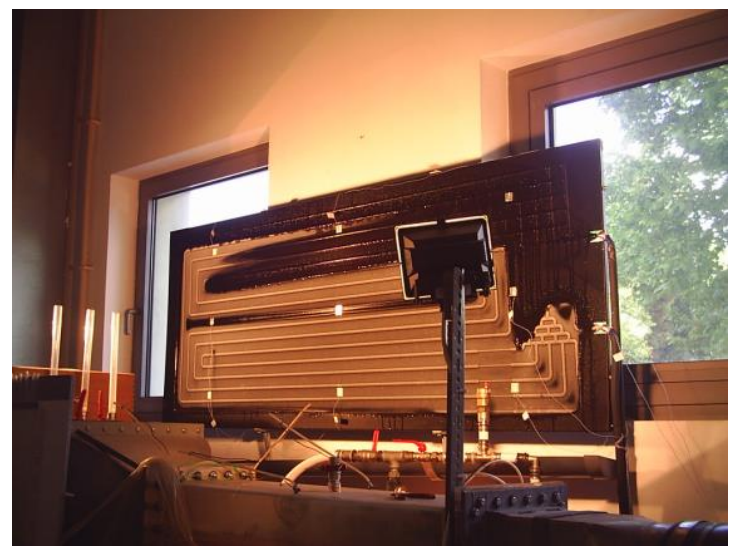

Figure 3: Plate evaporator

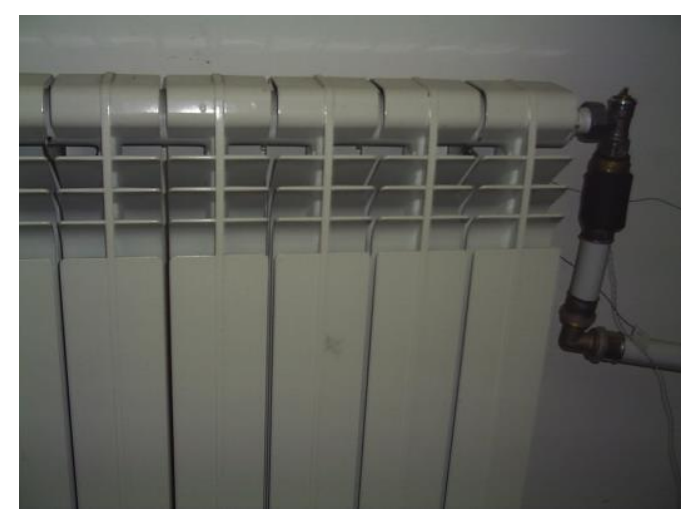

Figure 4: Radiator 


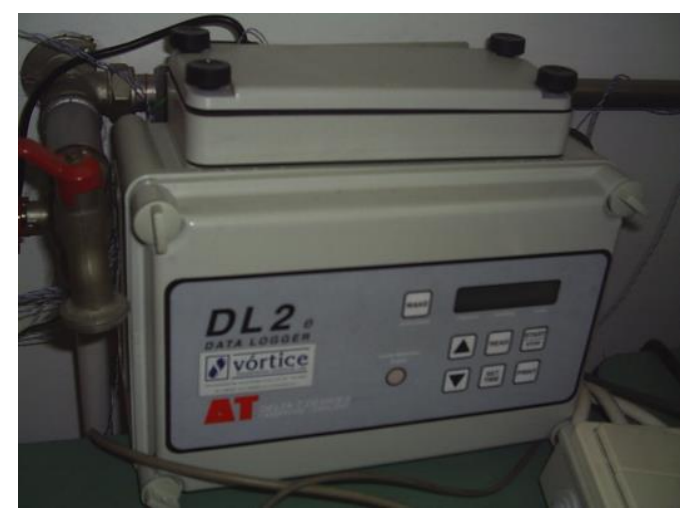

Figure 5: Data acquisition unit

\section{Results and discussions}

The analysis of experiments was made in a total duration of 24 hours for each reporting period. The process does not need constant supervision, that is, the data acquisition unit is automatic during the course of time. The results were analyzed by means of two modes: fully open and half open flow control valve.

\subsection{Energy dissipated by the radiator and electrical energy compressor}

The electric energy consumption of the compressor during the heat pump operation is shown in Fig. 6. This way, how greater the energy dissipated by the radiator, greater the energy consumption of the compressor will be. The COP of the system is obtained by the ratio of energy transferred to the radiator to the electric power consumption of the compressor.

\subsection{Analysis of the flow control valve}

Fig. 7 and 8 shows the first control mode: the fully open flow control valve with the results of energy dissipated by radiator, the compressor $\mathrm{COP}$ and the hot water flow rate. It can be seen that the increase of the flow rate and energy dissipated by radiator increase the system COP. Due to the hot water flow rate variation, greater pump consumption resulted in larger dissipation of energy by the radiator. 
ISSN: $1415-7314$

ISSN online: $2317-6717$

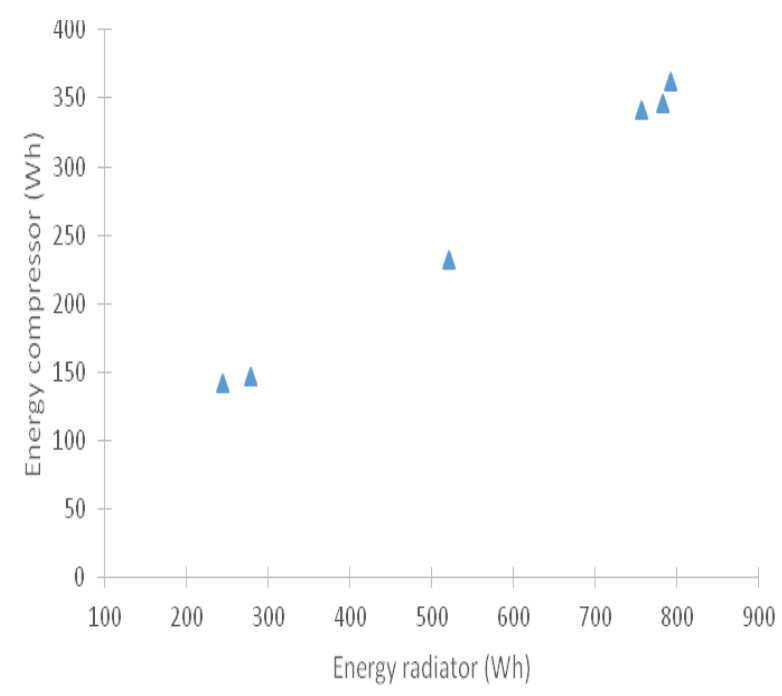

Figure 6: Energy dissipated by the radiator and energy compressor

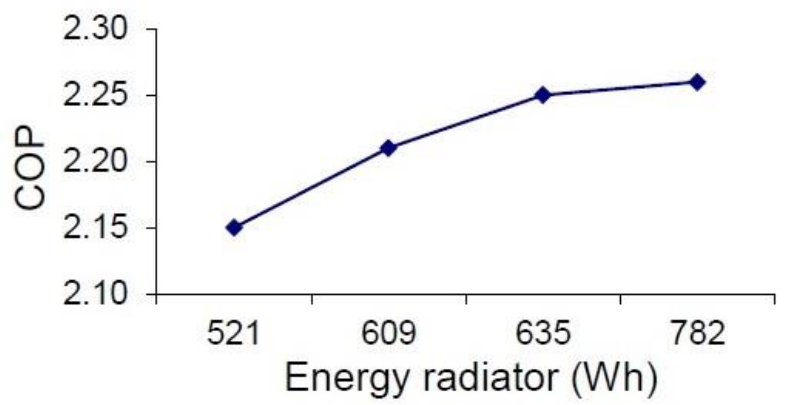

Figure 7: Valve fully open COP x energy radiator

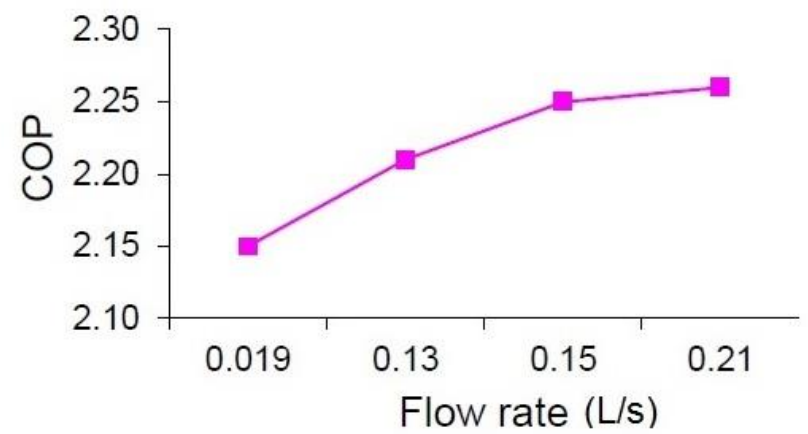

Figure 8: Valve fully open COP x flow rate 
Fig. 9 and 10 shows the second control mode: the half open flow control valve also with the results of energy dissipated by radiator, the system COP and the hot water flow rate. It can be seen that decreasing the hot water flow rate, it decreases the system COP also causing a decrease of energy dissipated by radiator. Therefore, the COP increases according the increase the energy dissipated by radiator, caused by varying the hot water flow rate controlled by flow valve.

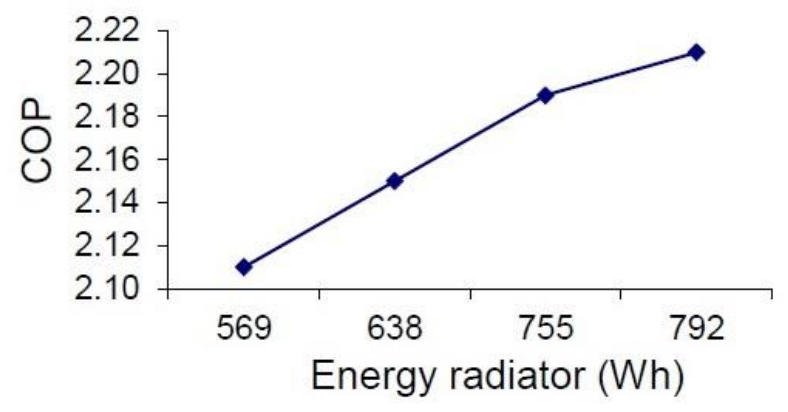

Figure 9: Valve half open COP x energy radiator

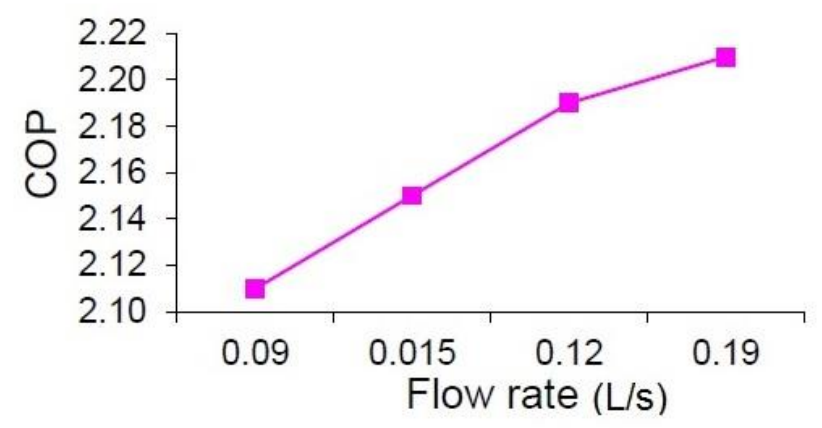

Figure 10: Valve half open COP $x$ flow rate

Fig. 11 shows the variation of temperature the water storage and energy radiator. It is expected that according to the temperature increase, greater is the energy dissipated by radiator.

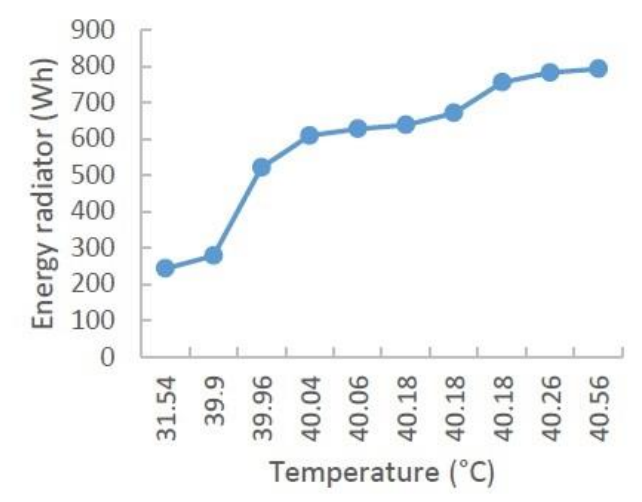

Figure 11: Energy radiator $x$ temperature the water storage 


\section{Conclusions}

This paper investigated the thermal performance of a domestic hot water (DHW) and space heating installation with analysis of the electric energy consumption of the compressor and energy dissipated by the radiator. It was observed that it is not recommended that radiators work with their reduced hot water flows rate, thus compromising the release of thermal energy and the consequent decrease in the COP. The energy consumed by the compressor will depend exclusively on thermal energy dissipated by the radiators. The lower the energy transferred by the radiators, the lower the energy consumed by the compressor.

\section{Acknowledgements}

The authors thank to the Superior Institute of Engineering of Porto to their providing support for this research.

\section{References}

Bakirci, K. Yuksel, B. Experimental thermal performance of a solar source heat-pump system for residential heating in cold climate region. Applied Thermal Engineering (2011) 31 15081518.

Banister C. J. William R. W. Michael R. C. Solar-assisted heat pump test apparatus. Science Direct, (2014) 48, 489-498.

Chaturvedi, S. K. Abdel Salam, T. M. Sreedharam S. S. Gorozabel, F. B. Two-stage direct expansion solar-assisted heat pump for high temperature applications. Applied Thermal Engineering (2009) (10) 29, 2093-2099.

Hepbasli, A, Kalinci Y. A. Review of heat pump water heating systems. Renew Sust Energy Rev, (2009) 13, 1211-29.

Moreno, A. R. Gonzales-Gil, A. Izquierdo, M. Hernando, N. G. Theoretical model and experimental validation of a direct-expansion solar assisted heat pump for domestic hot water applications. Energy (2012) 45, 704-715.

Wagar, W. R. Banister, J. C. Michael R. C. Validation of a single tank, multi-mode solarassisted heat pump TRNSYS model. Science Direct, (2014) 48, 499-504.

Wang, R. Z. Li, Y. W. Wu, J. Y. Xu, Y. X. Experimental performance analysis on a directexpansion solar-assisted heat pump water heater. Science Direct, (2007) 27, 2858-2868. 